\title{
Knowledge and expectations of labour pain and pain relief among primigravid women
}

\author{
Priya Sachin Sadawarte $^{1^{*}}$, Anjali Bhure ${ }^{2}$ \\ Assistant Professor ${ }^{1}$, Professor and Head ${ }^{2}$, Department of Anaesthesia, NKP SIMS, Nagpur, Maharashtra \\ state, India.
}

*Corresponding author: drpriyasadawarte@gmail.com

\begin{abstract}
We analysed knowledge and expectations of pain of labour and knowledge of labour analgesia methods among primigravida women attending an antenatal care clinic in a teaching hospital in a rural part of central India. The results of this study could be utilized to improve the analgesic care of women.
\end{abstract}

\begin{abstract}
Material and method
Qualitative analysis of data obtained from semi-structured interviews of 100 primigravida attending antenatal care. We studied previous painful experiences, knowledge and expectation oflabour pain, attitude towards labour pain, and knowledge of labour analgesia methods.
\end{abstract}

\begin{abstract}
Results
Patients were poorly informed about pain of labour. Many women appeared highly motivated concerning their ability to cope with labour. All the patients expected pain, many of them expected pain to be severe but had no concept of duration of the pain, and knew very little concerning methods available for pain relief in labour.
\end{abstract}

\section{Conclusion}

Women attending antenatal care clinic in teaching hospital in rural part of central India were poorly prepared for the experience of delivery. Antenatal programmes should incorporate education concerning pain of labour and methods available to alleviate pain.

Keywords: primigravida; labour pain; labour analgesia

\section{Introduction}

Traditionally, young women are educated about pregnancy and labour by female elders, although this information may have included some misconceptions. The aim of this study was to determine the knowledge and expectations of primigravida women regarding labour pain and pain relief methods. The results of this study could be utilized to improve the analgesic care of these women.

\section{Materials and Methods}

The study population for this prospective study consisted of 100 primigravida women presenting for antenatal care to a teaching hospital in rural part of central India. Only primigravid patients were recruited, in order to have a homogeneous cohort with no previous personal experience of labour. Women were interviewed during the third trimester of pregnancy.

\section{Inclusion criteria}

1. Willingness to participate

2. Ability to converse in Marathi, Hindi or English Written informed consent was obtained from all participants after obtaining study approval from the Hospital Ethics Committee.

Informants were interviewed alone in a quiet room at the hospital by one of the investigators. An open-ended interview guide explored the following themes: previous experience of pain, expectations of and attitudes towards labour pain, and knowledge of labour analgesia methods. A 10point VAS was used to score the severity of 
previous pain experience and the expected severity of labour pain $(0=$ no pain, $10=$ worst imaginable pain).

Data analysis followed the principles of descriptive analysis. Numerical and operationally defined verbal counting was employed. ${ }^{1}$ In this study, 'few' referred to more than one but less than ten informants. The words 'some' and 'several' were used for groups of 11 - 50 participants, with 'some' referring to the lower numbers and 'several' to the upper numbers in this range. The term 'many' was applied for between 50 and 75 parturients, while 'most' and 'the majority' were utilised synonymously to indicate that 76 or more of the informants were involved in a particular theme or finding.

\section{Results}

\section{$\underline{\text { Socio demographic Data }}$}

Table 1. Demographic data

\begin{tabular}{|ll|}
\hline Demographic data & Frequency \\
Age (Years) & \\
$18-20$ & 18 \\
$21-25$ & 73 \\
$25-30$ & 9 \\
\hline
\end{tabular}

Table 2. Education

\begin{tabular}{|ll|}
\hline Education & Frequency \\
No Education & 3 \\
Primary schooling & 3 \\
$1-4$ years of secondary & 7 \\
schooling & 14 \\
$10^{\text {th }}$ class & 67 \\
$12^{\text {th }}$ class & 6 \\
Graduate & \\
\hline
\end{tabular}

Table 3. Occupation

\begin{tabular}{|ll|}
\hline Occupation & \\
Employed & 9 \\
Unemployed & 91 \\
\hline
\end{tabular}

Knowledge of labour pain

In response to the open-ended question 'What do you know about labour?' majority of women initially said they know nothing at all regarding labour and some said that knowledge of labour could only be obtained when they experience labour. All the women indicated that they knew that labour would be painful. Sources of information varied. 85women said they had received information from their mothers, sisters or female friends. Eight patients said that doctors attending to them in antenatal clinic had told them about labour pain. Seven patients said that they had observed it in movies. Only one participant had read about labour pain in a women's magazine.

\section{Previous pain experiences}

Thirty one women said that they had previously experienced severe pain. The mean score on the 10-point VAS scale for the worst pain experienced in the past was 6.1 (range 0 - 10). Twelve informants felt that they had suffered the worst imaginable pain in the past (pain score 10). For three women this pain was associated with a fracture of arm or leg, for three it was associated with dysmenorrhoea, for two women dental pain, one each spoke about backache, pain after surgery for breast swelling, burn injury and renal colic.

Personal expectations of severity and duration of labour pain

Table 4. Expectation of severity and duration of labour pain

\begin{tabular}{|ll|}
\hline Expected severity of labour pain (VAS) \\
\hline$<3$ & 4 \\
$4-7$ & 11 \\
$8-10$ & 72 \\
No idea & 13 \\
\hline Expected duration of labour pain (Hrs) & \\
\hline$<1 \mathrm{hr}$ & 9 \\
$1-5 \mathrm{hrs}$ & 9 \\
$>5 \mathrm{hrs}$ & 58 \\
No idea & 24 \\
\hline
\end{tabular}

Twenty seven women thought labour pain is good. Ten women thought pain is an integral part of the normal delivery process. Few women were unsure whether labour pain was good or bad. A few were neutral.

Majority said that the pain should be relieved if it can be done without harming baby. This included many of the women who thought that labour pain 
was 'a good thing'. Some of these women wanted to experience pain, but emphasized that the pain should not be allowed to get too severe or last too long. Four women wanted pain relief but feared that pain relief methods may harm baby. Many women said they would like to know about pain relief methods and use those methods. But they felt that their family members, especially mother in law and husband, may not allow it. Twenty women expressed the opinion that labour pain should not be relieved. Several women thought there is no need of labour analgesia as women are delivering without pain relief methods, pain is important for bonding between mother and child and it's a part of natural delivery process. Four women were not sure whether labour pain should be relieved. None of the patients knew about adverse effects of labour pain.

Sixty nine women thought they would be able to cope with the pain of labour, seventeen thought they need support. Fourteen were less sure about their coping skills, yet appeared very motivated. One woman felt if she is already familiar with the labour room, she would be more in control and able to cope better. Seventeen women said they did not think they would cope with the pain of labour. Out of the seventeen ten thought that cesarean section is better than experiencing pain. Fourteen said they don't know whether they would be able to cope unless they experience it.

Table 5. Need to relieve labour pain and coping skills

\begin{tabular}{|l|l|}
\hline Should labour pain be relieved & Frequency \\
\hline Yes & 76 \\
No & 20 \\
No opinion & 4 \\
\hline \multicolumn{2}{|l|}{} \\
\hline Coping Skills & \\
\hline Yes & 69 \\
No & 17 \\
Not sure & 14 \\
\hline
\end{tabular}

Knowledge of analgesia

Majority of women were poorly informed about methods of labour analgesia. Several informants said that pain was a natural part of childbirth, and that no method existed to alleviate this pain. Many referred to 'tablets' and 'injections'. A few said that they had heard that breathing methods existed and a few talked about acupressure but further said that they are unaware of any details. A few informants forwarded limited information about the possibility of 'a gas to breathe'. One woman said she had read about 'injection in the back' and hydro birth in a magazine.

Table 6. Knowledge about labour analgesia

\begin{tabular}{|l|l|l|}
\hline Question & Answer & Frequency \\
\hline $\begin{array}{l}\text { Awareness about } \\
\text { labour analgesia }\end{array}$ & Yes & 64 \\
& No & 36 \\
\hline $\begin{array}{l}\text { Knowledge about } \\
\text { types of labour } \\
\text { analgesia }\end{array}$ & & \\
\hline \multicolumn{2}{|c|}{ Tablets and } & 60 \\
& Injections & 9 \\
& Breathing & 8 \\
& exercises & 6 \\
& Gas to breath & 1 \\
& Acupressure & 1 \\
& Injection in back & 1 \\
& Hydro birth & 0 \\
& TENS/Hypnosis & \\
& &
\end{tabular}

(Some women were aware about more than one method.)

Many women appeared to rely on the nursing staff to provide both pain relief and emotional support. Some women expected doctors who will conduct their delivery (Obstetricians) to assist them with their pain. Asked whether they wanted a relative or friend to offer emotional support during labour, many women said that they wanted their mother, sister or a female relative to be present, a few wanted their husband to be with them during delivery. A few women, however, indicated that they only wanted medical staff in attendance.

\section{Discussion}

This study assessed the knowledge and expectations of pain of labour and labour analgesia methods among primigravid women attending antenatal clinic in central India. 
In addition to knowledge and expectations of the pain of labour, antenatal education, cultural and social background and the presence of persons supporting the parturient, also influence the experience of pain in labour. ${ }^{2-5}$ Expectations include the mother's belief in her ability to cope up with pain. Antenatal education regarding labour is important as it reduces anxiety, enhances feelings of control, and correlates with a good experience of childbirth. In contrast, anxiety about the pain of labour may result in negative experiences in labour. ${ }^{6}$ Experience of labour is important as it may impact on quality of subsequent mothering. ${ }^{\text {? }}$

These women may be less educated than women from the western world therefore have poorer knowledge about human reproduction and they have limited access to information. Many of them are not employed; hence seeking information from a source outside home is difficult for them. Thus they are dependent on education provided by female relatives. This makes antenatal education during antenatal checkups even more important. Because of their poor knowledge about labour pain and relief methods, these parturients are dependent on the health care workers and their assessment of pain for analgesic needs in labour.

Currently, many patients are in advanced labour when first encountered by the anaesthetist for labour analgesia. Obtaining informed consent from women who are in pain and who have no preexisting information of the risks and benefits of epidural analgesia is a problem and is controversial. ${ }^{6,8}$ Women may experience anxiety when they are informed about options for analgesia for the first time during labour, and consequently may refuse pain relief.

Many women in this study expected labour pain to be severe, as against a study done by Hug, in which he found that many Indian women expected pain but had no idea about severity. ${ }^{9}$ This may be because with passing time, knowledge about labour might have improved.

Many were highly motivated to deal with labour pain, although some were anxious, and a few women expressed fear. F Ibach et al found similar results when they studied women in Africa. ${ }^{10}$
None of the patients knew about adverse effects of labour pain and why it should be relieved. The fact that some informants in this study considered pain a positive feature of labour and that a few opposed the idea of relieving labour pain, may reflect traditional social values, according to which labour pain is welcomed, and successful bonding is seen to depend on the experience of pain in labour. Women in India are raised from birth to accept and endure the pain of childbirth and other pain. This may be the reason behind high level of motivation to deal with labour. Hug also found that many Indian women were ready to tolerate labour pain. ${ }^{9}$

Participants had limited knowledge of labour pain and methods used for labour analgesia. Many women said that they would like to know about labour analgesia and use it, but their family, especially mother in law and husband, may not allow use. Hence there is a need to educate not just pregnant women but society as a whole including men and elderly women. Hug found that women did not know about epidural labour analgesia but were ready to ask for it when informed. ${ }^{9}$

Our findings indicate that primigravida were inadequately prepared for the experience of childbirth. Women coming to hospital for antenatal checkup may be sensitized about labour pain and pain relief methods towards the end of first trimester, so they get sufficient time to know and think more about it before taking the final decision. In last few antenatal checkups, they may be told about labour pain and analgesia. They may be taken to labour room so that they are familiar with it and they know what to expect thus reducing their anxiety. This may be done by health care workers trained as childbirth educators. Better penetration of knowledge regarding labour and pain relief to grass root level is possible. This form of antenatal education should improve women's experience of childbirth, as well as enhance patient autonomy and ability to access pain relief in labour.

We need to study impact of this antenatal counseling on expectation of pain and knowledge about pain relief methods. 


\section{Conclusion}

Women at this hospital in rural India were poorly informed and hence poorly prepared for the experience of labour. Most expected pain, but had no concept of the severity or duration of the pain. Most women appeared highly motivated concerning their ability to cope with labour, and knew very little concerning methods available for pain relief in labour. Antenatal programmes should incorporate sensitive education concerning pain of labour and the methods available to alleviate pain.

\section{References}

1. Sandelowski M. Real qualitative researchers do not count: the use of numbers in qualitative research. Res Nurs Health 2001; 24: 230-240 http://dx.doi.org/10.1002/nur.1025 PMid:11526621

2. Capogna G, Alahuhtat S, Celleno D et al. Maternal expectations and experiences of labour pain and analgesia: a multicentre study of nulliparous women.

Int J ObstetAnesth1996; 5:229-235. http://dx.doi.org/10.1016/S0959-289X(96)80042$\underline{2}$

3. Hallgren A, Kihlgren M, Norberg A, Forslin L. Women's perceptions of childbirth and childbirth education before and after education and birth. Midwifery 1995; 11: 130-137. http://dx.doi.org/10.1016/0266-6138(95)90027-6

4. Hofmeyr GJ, Nikodem VC, Wolman WL, Chalmers BE, Kramer T. Companionship to modify the clinical birth environment: effects on progress and perceptions of labour, and breast feeding. $\mathrm{Br} \mathbf{J}$ ObstetGynaecol1991; 98: 756-764. http://dx.doi.org/10.1111/j.1471528.1991.tb13479.x

PMid:1911582

5. Paech MJ, Gurrin LC.A survey of parturients using epidural analgesia during labour. Considerations relevant to antenatal educators.Aust N Z J

ObstetGynaecol1999; 39: 21-25. http://dx.doi.org/10.1111/j.147928X.1999.tb03436. PMid:10099742

6. de Roubaix JAM. Seeking patient's consent in anaesthesiology: consent in clinical practice. South African Journal of Anaesthesia and Analgesia 2006; 11: 125-129.

7. Lundgren I, Dahlberg K. Women's experience of pain during childbirth. Midwifery 1998; 14:105-110. http://dx.doi.org/10.1016/S0266-6138(98)90007-9

8. Jenkins K, Baker AB. Consent and anaesthetic risk. Anaesthesia2003; 58: 962-984. http://dx.doi.org/10.1046/j.1365-044.2003.03410.x PMid:12969038

9. Hug I, Chattopadhyay C, Roy Mitra G, Mukherjee KarMahapatra R,Schneider MC. Maternal expectations and birth-related experiences: a survey of pregnant women of mixed parity from Calcutta, India. Int J ObstetAnesth.2008;17 ;2;112-117. http://dx.doi.org/10.1016/j.ijoa.2007.10.004 PMid:18295472

10. Ibach F, Dyer RA, Fawcus S, Dyer SJ. Knowledge and expectations of labour among primigravid women in the public health sector. SAMJ. 2007;97;6; 461-464 